\title{
The Efficacy of Sugammadex in the Monitoring of Motor Evoked Potentials for Spine Surgery: A 10 Cases Review
}

Daehee Suh M.D, Joonho Cho, M.D, Byounghoon Yoo, M.D, Ph.D, Sangseok Lee, M.D*

Department of Anesthesiology and Pain Medicine, Sanggye Paik Hospital, Inje University College of Medicine, Seoul, Korea

DOI: $10.36347 /$ sjmcr.2020.v08i08.008

| Received: 30.07 .2020 | Accepted: 07.08.2020 | Published: 13.08.2020

*Corresponding author: Sangseok Lee, M.D

Abstract

Motor evoked potentials (MEPs) monitoring has been applied for an early detection of the intraoperative neurologic injury. As a landmark, baseline MEPs should be accurately measured before surgical interventions. Many anesthetics, especially neuromuscular blocking agents can attenuate MEPs, and residual neuromuscular blocking effects can interfere with accurate interpretation of MEPs. Therefore, it should be antagonized completely and rapidly before measuring the baseline MEPs. We evaluated the efficacy of sugammadex in antagonizing the residual effect of rocuronium for 10 patients. In all patients with administration of sugammadex dose of 2-4 mg/kg, neuromuscular blockade was completely reversed within 5 minutes after administration of sugammadex, even in the case with deep neuromuscular block (TOF count 0). Appropriate MEPs amplitudes were measured during the surgery after reversal, with previous mild, moderate even deep neuromuscular blockade depths. The residual effect of neuromuscular blockade before MEPs monitoring in spine surgery should be completely reversed, and the sugammadex showed a good efficacy in neuromuscular blockade reversal.

Keywords: Anesthetics intravenous, Propofol, Remifentanil; neuromuscular blocking agents, rocuronium; sugammadex; Evoked Potentials, Motor.

Copyright @ 2020: This is an open-access article distributed under the terms of the Creative Commons Attribution license which permits unrestricted use, distribution, and reproduction in any medium for non-commercial use (NonCommercial, or CC-BY-NC) provided the original author and source are credited.

\section{INTRODUCTION}

Motor evoked potentials (MEPs) monitoring has been indicated to prevent irreversible neurologic injury during spinal or neurosurgical operations. As a landmark, accurate measurement of baseline MEPs should be established before surgical interventions. Many anesthetics, especially neuromuscular blocking agents (NMBAs) can attenuate MEPs. Rocuronium is usually used to facilitate tracheal intubation during anesthetic induction. However, the clinical duration (time from injection of the intubation dose to the recovery of twitch to $25 \%$ of control) of rocuronium was usually about 36 minutes [1]. Therefore, effects of residual neuromuscular blockade can interfere with accurate interpretation of baseline MEPs, and it should be antagonized completely and rapidly before measuring the qualified baseline MEPs. Classical reversal method using an anticholinesterase may be ineffective in this situation because it cannot antagonize deep neuromuscular blockade even at a high dose due to the ceiling effect of an anticholinesterase reversal [2]. As an alternative technique, some individuals recommend avoiding neuromuscular blockade and instead use deep inhalational anesthesia or high dose short-acting opiates for intubation [3]. However, these techniques can be associated with a higher incidence of airway trauma [4] or hypotension [5]. Recently, sugammadex (Bridion ${ }^{\circledR}$, MSD, New Jersey, USA) has been used in the surgery under MEPs monitoring [6, 7]. It can rapidly antagonize the action of amino-steroid NMBAs at any depth of neuromuscular blockade without potential side effects of classic reversal drugs [8].

We present cases of 10 patients relating to efficacy of sugammadex in reversing the mild, moderate, and deep rocuronium-induced neuromuscular blockade before MEPs monitoring.

\section{Case Presentation}

\section{Anesthesia and monitoring}

We evaluated the effect of sugammadex on MEPs for reversal of the residual rocuronium-induced neuromuscular blockade in 10 patients undergoing elective spine surgery with MEPs monitoring. Propofol (plasma concentration target-controlled infusion 3.0-3.5 $\mu \mathrm{g} / \mathrm{ml})$ and remifentanil $(0.15-0.3 \mu \mathrm{g} / \mathrm{kg} / \mathrm{min})$ were used to induce and maintain general anesthesia and 
rocuronium $(0.6 \mathrm{mg} / \mathrm{kg})$ was used only to facilitate tracheal intubation.

After confirming surgical position, neuromuscular monitoring by train-of-four (TOF) stimulation, was applied by acceleromyography (TOFWatch $^{\circledR}$, Organon Teknika BV, Netherlands). The baseline of MEPs (NIM-SPINE ${ }^{\circledR}$, Medtronic, Ireland) was measured 3 minutes after the first TOF stimulation. The intensity of MEPs stimulator was 150-200 mA. If the depth of neuromuscular block would be deep (TOF count $=0$ ) or profound block (Post-tetanic count $\leqq 3$ ) and/or the baseline values of MEPs would show a low or poor response, then sugammadex $2-4 \mathrm{mg} / \mathrm{kg}$ was given intravenously. After confirming TOF-ratio $\geqq$ $90 \%$, baseline MEPs was measured again. Then, the surgical procedure began, and we did not use muscle relaxants for surgical relaxation. TOF-ratios were maintained as almost 100\% (unparalyzed) until the end of the procedure.

\section{Summary of 10 patients}

The average age is $68.4 \pm 5.8$ (mean \pm SD) years and body weight is $60.5 \pm 11.0 \mathrm{~kg}$. Total administered dose of rocuronium before baseline MEPs is $0.67 \pm 0.1 \mathrm{mg} / \mathrm{kg}$. Sugammadex was administered at $49.8 \pm 11.9$ minutes after anesthesia induction. The neuromuscular block was completely reversed within 5 minutes after the administration of sugammadex even in the case of deep neuromuscular block (TOF count 0 in patient \#2 and \#3). And after that, appropriate MEP value was measured during the surgery. We classified into three categories based on the response of TOFstimulation before the administration of sugammadex, which is mild (TOF count 4, 3 patients), moderate (TOF count 1-3, 5 patients), and deep (TOF count 0,2 patients) block group. The dose of sugammadex was 4 $\mathrm{mg} / \mathrm{kg}$ in 3 patients (TOF count $=0,1$ ), $2 \mathrm{mg} / \mathrm{kg}$ in 7 patients (TOF count $\geq 2$ ). All patients after reversing by sugammadex showed TOF-ratio $=100 \%$. And the ranges of values were checked from all extremities of each patient.

After the administration of sugammadex for each extremity, the increased rate of MEP values was calculated for each site (Table 1). The first group included patients with a TOF count of 0 (patient \#2, \#3). After the administration of sugammadex, the MEP values were maximally increased by 67 -fold and the average increase rate on all extremities in two patients was 27 -fold. The second group included patients with a TOF count of 1-3 (patient \#1, \#4, \#8, \#9, \#10). After the administration of sugammadex, the MEP values were maximally increased by 31 -fold and the average MEP value increase rate on all extremities in five patients was 6.4-fold. The third group included patients with a TOF count of 4 or more (patient \#5, \#6, \#7). After the administration of sugammadex, the MEP value was maximally increased by 58 -fold and the average MEP value increase rate on all extremities in three patients was 9-fold.

At some sites (right foot of patient \#1, the right foot of patient \#4, the left foot of patient \#6, and right foot of patient \#8), the MEP value was less than $100 \mu \mathrm{V}$ even after administration of sugammadex, which means there was a certain degree of neurologic weakness not produced by neuromuscular blocker. Even in those sites, the MEP value was maximally increased by 8.4 fold and 4.9-fold on average of all those sites.

\section{Discussions And Conclusions}

Motor evoked potentials monitoring has been used to detect the possible neuronal injury during spinal or neurosurgical operations. The use of nondepolarizing NMBAs during induction and intubation is common in spine surgery under general anesthesia. However, residual neuromuscular blocking effects until the time of MEPs stimulation can interfere with accurate interpretation of baseline MEPs. This should be antagonized, completely, and rapidly before measuring the qualified baseline MEPs. The ability of sugammadex to quickly restore neuromuscular conduction may allow the unlimited use of rocuronium or vecuronium during anesthesia induction before neurophysiologic monitoring [9, 10]. This application of sugammadex has been successfully used for patients requiring neurophysiologic monitoring during the brain and spinal cord surgeries [6, 7, 11]. Before the introduction of sugammadex in clinical practice, standard practice had been to allow spontaneous recovery of motor function or reversal with cholinesterase inhibitors before neurophysiologic monitoring or avoiding neuromuscular blockade for intubation by using deep inhalational anesthesia or high dose short-acting opiates [3]. The non-relaxant induction method is not recommended because of the following. Adding NMBAs to an induction regimen significantly improved the quality of tracheal intubation and decreased postoperative hoarseness and vocal cord sequelae [4]. The use of cholinesterase inhibitors or relying on spontaneous recovery may hinder obtaining a true evaluation of baseline motor function. Baseline motor function allows reliable comparison with intraoperative events and appropriate identification of conduction disturbances. NMBAs-induced decreased baseline values risk a false assumption of true normal patient-specific values. Therefore, subsequent early mild suppressions may go unnoticed.

The classical intraoperative wake-up test has been a gold standard in patients with a possible neuronal injury during spine surgery although it has been less used than MEPs monitoring. The anesthetic regimen should be chosen in the means of rapid and cooperative recovery. Sugammadex may also the best agent for the purpose it [12]. 
We found an interesting point in our patient \#5, which should be emphasized in the efficacy of sugammadex for MEP monitoring. Although some amount of reversal of neuromuscular block was observed before administration of sugammadex in patient \#5 (TOF-ratio recovery with 27\%), the MEP value of left foot was significantly increased by 58 -fold after administration of sugammadex (from 42 to 2473 $\mu \mathrm{V})$. It means that a full reversal of neuromuscular block may be needed for appropriate MEP amplitude for the surgery.

The authors have some concerns before using sugammadex. First, sudden movement of the patient may occur when the patient becomes completely nonrelaxed after using sugammadex. However, such concerns have not arisen by maintaining enough anesthesia depth prior to the sugammadex administration. Further research into an anesthetic regimen that can limit the patient's sudden movement, which is generally applicable to most patients, should be supported in the future. Second, there were concerns about side effects such as hypersensitivity reactions and severe bradycardia caused by using sugammadex. However, no adverse events were observed in any case. Subsequent studies focusing on the side effects associated with sugammadex use should continue to be supported to draw more general conclusions.

\section{CONCLUSION}

Accurate measurement of baseline values during MEPs monitoring is important, which can be interrupted by the residual effects of muscle relaxants used for tracheal intubation. Therefore, it is necessary to completely reverse the residual effect of the neuromuscular block before MEPs monitoring. We report that sugammadex shows good efficacy in reversing residual rocuronium-induced neuromuscular block before MEPs monitoring in spine surgery.

Table-1: Summary of cases

\begin{tabular}{|c|c|c|c|c|c|c|c|c|c|c|}
\hline \multirow[t]{2}{*}{ Case } & \multirow[t]{2}{*}{$\begin{array}{l}\text { Age } \\
\text { (yrs) }\end{array}$} & \multirow[t]{2}{*}{$\begin{array}{l}\text { Weight } \\
\text { (Kg) }\end{array}$} & \multirow[t]{2}{*}{$\begin{array}{l}\text { Rocuronium } \\
(\mathrm{mg} / \mathrm{kg})\end{array}$} & \multirow{2}{*}{$\begin{array}{l}\text { Time } \\
\text { interval } \\
\text { (min) }\end{array}$} & \multirow{2}{*}{$\begin{array}{l}\text { Sugammadex } \\
(\mathrm{SGX}) \\
(\mathrm{mg} / \mathrm{kg})\end{array}$} & \multicolumn{2}{|c|}{ TOF count (ratio) } & \multicolumn{2}{|c|}{$\begin{array}{l}\begin{array}{l}\text { Amplitude of } \\
\text { (Hand Lt-Rt / Foot Lt-Rt) }\end{array} \\
\end{array}$} & \multirow[t]{2}{*}{ Diagnosis } \\
\hline & & & & & & $\begin{array}{l}\text { Before } \\
\text { SGX }\end{array}$ & $\begin{array}{l}\text { After } \\
\text { SGX }\end{array}$ & $\begin{array}{l}\text { Before } \\
\text { SGX }\end{array}$ & After SGX & \\
\hline 1 & 68 & 66 & 0.61 & 56 & 2 & 2 & $4(100 \%)$ & $\begin{array}{l}127-33 / \\
42-28\end{array}$ & $\begin{array}{l}382-397 / \\
253-85\end{array}$ & $\begin{array}{l}\text { Cervical } \\
\text { myelopathy, C5-7 }\end{array}$ \\
\hline 2 & 61 & 49 & 0.91 & 41 & 4 & 0 & $4(100 \%)$ & $\begin{array}{l}83-116 / \\
36-151\end{array}$ & $\begin{array}{l}2355-2080 / \\
2417-873\end{array}$ & $\begin{array}{l}\text { Lumbar } \\
\text { degenerative } \\
\text { kyphoscoliosis } \\
\text { L1-4 }\end{array}$ \\
\hline 3 & 78 & 80 & 0.63 & 33 & 4 & 0 & $4(100 \%)$ & $31-50 / 8-7$ & $\begin{array}{l}595-600 / 7- \\
8\end{array}$ & HIVD T10-11 \\
\hline 4 & 69 & 64 & 0.63 & 45 & 2 & 2 & $4(100 \%)$ & $\begin{array}{l}728-512 / \\
139-7\end{array}$ & $\begin{array}{l}1858-1398 / \\
1412-59\end{array}$ & HLD L1-2-3-4 \\
\hline 5 & 72 & 47 & 0.64 & 50 & 2 & $4(27 \%)$ & $4(100 \%)$ & $\begin{array}{l}1701-519 / \\
42-78\end{array}$ & $\begin{array}{l}4755-9134 / \\
2473-1097\end{array}$ & $\begin{array}{l}\text { s/p PD L3-4-5 \& } \\
\text { PF T11-S1 }\end{array}$ \\
\hline 6 & 74 & 70 & 0.64 & 57 & 2 & 4 & $4(100 \%)$ & $\begin{array}{l}1296-527 / \\
10-18\end{array}$ & $\begin{array}{l}2049-1200 / \\
42-20\end{array}$ & $\begin{array}{l}\text { r/o Epidermal } \\
\text { cyst, r/o Synovial } \\
\text { cyst C7-T1 }\end{array}$ \\
\hline 7 & 71 & 60 & 0.63 & 65 & 2 & $4(26 \%)$ & $4(100 \%)$ & $\begin{array}{l}1525- \\
1657 / 119- \\
631\end{array}$ & $\begin{array}{l}2206-2411 / \\
207-601\end{array}$ & IDEM tumor T5-6 \\
\hline 8 & 68 & 57 & 0.61 & 42 & 2 & 3 & $4(100 \%)$ & $\begin{array}{l}850-744 / \\
97-10\end{array}$ & $\begin{array}{l}1232-1772 / \\
215-39\end{array}$ & $\begin{array}{l}\text { Chronic cauda } \\
\text { equina SD, s/p PD } \\
\text { \& PLF L3-S1 }\end{array}$ \\
\hline 9 & 59 & 66 & 0.6 & 43 & 2 & 2 & $4(100 \%)$ & $\begin{array}{l}1444- \\
748 / 489- \\
827\end{array}$ & $\begin{array}{l}2052-1225 / \\
930-1106\end{array}$ & OPLL C3-4-5-6 \\
\hline 10 & 74 & 70 & 0.6 & 33 & 4 & 1 & $4(100 \%)$ & $\begin{array}{l}144- \\
86 / 495-263\end{array}$ & $\begin{array}{l}1984- \\
2658 / 1375- \\
151\end{array}$ & HIVD T12-L1 \\
\hline
\end{tabular}

HIVD: herniated inter vertebral disc, HLD: herniated lumbar disc, PD: posterior decompression, PLIF: posterior lumbar interbody fusion, IDEM: Intradural- extramedullary, OPLL: ossification of posterior longitudinal ligament

\section{ACKNOWLEDGEMENT}

We deeply thank our colleagues (Dr. Dong Reul Lee, Dr. Yeong Deok Kim, and Dr. Joon-hee Lee) for their great contribution of preliminary data collection;

\section{REFERENCES}

1. Naguib M. Neuromuscular effects of rocuronium bromide and mivacurium chloride administered alone and in combination. Anesthesiology. 1994;81(2):388-95.

2. Bartkowski RR. Incomplete reversal of pancuronium neuromuscular blockade by neostigmine, pyridostigmine, and edrophonium. Anesth Analg. 1987;66(7):594-8.

3. Erhan E, Ugur G, Alper I, Gunusen I, Ozyar B. Tracheal intubation without muscle relaxants: 
remifentanil or alfentanil in combination with propofol. Eur J Anaesthesiol. 2003;20(1):37-43.

4. Mencke T, Echternach M, Kleinschmidt S, Lux P, Barth V, Plinkert PK, Fuchs-Buder T. Laryngeal morbidity and quality of tracheal intubationa randomized controlled trial. Anesthesiology:. 2003 May 1;98(5):1049-56.

5. In J, Shin HI, Chung SH, Kim KO, Choi JG, Lee $\mathrm{Y}$, Cho H. Effect-site concentration of remifentanil for smooth tracheal intubation without muscle relaxants provokes hypotension under desflurane anesthesia. Korean J Anesthesiology. 2008 Jul 1;55(1):31-5.

6. Batistaki C, Papadopoulos K, Kalimeris KA, Soultanis K, Alevizou A, Pantazi M, Kostopanagiotou GG. Sugammadex to reverse rocuronium and facilitate intraoperative motor evoked potentials monitoring during spinal surgery. Anaesthesia and Intensive Care. 2012 Nov 1;40(6):1073-5.

7. Reid S, Shields MO, Luney SR. Use of sugammadex for reversal of neuromuscular blockade in 2 patients requiring intraoperative neurophysiological monitoring. J Neurosurgical Anesthesiology. 2011 Jan 1;23(1):56-7.
8. Fuchs-Buder T, Meistelman C, Raft J. Sugammadex: clinical development and practical use. Korean J Anesthesiol. 2013;65(6):495-500.

9. Hashimoto $\mathrm{Y}$, Gotanda $\mathrm{Y}$, Ito $\mathrm{T}$, Ushijima K. Recovery from rocuronium by sugammadex does not affect motor evoked potentials. Masui. 2011;60(8):968-71.

10. Pavoni V, Gianesello L, De Scisciolo G, Provvedi E, Horton D, Barbagli R, Conti P, Conti R, Giunta F. Reversal of profound and" deep" residual rocuronium-induced neuromuscular blockade by sugammadex: a neurophysiological study. Minerva Anestesiologica. 2012 Feb 1;78(5):542-9.

11. Trifa M, Krishna S, D'Mello A, Hakim M, Tobias JD. Sugammadex to reverse neuromuscular blockade and provide optimal conditions for motorevoked potential monitoring. Saudi J Anaesth. 2017;11(2):219-21.

12. Biricik E, Alic V, Karacaer F, Celiktas M, Unlugenc H. A comparison of intravenous sugammadex and neostigmine + atropine reversal on time to consciousness during wake-up tests in spinal surgery. Niger J Clin Pract. 2019;22(5):60915. 